\title{
Evaluating The Impact of Roads On The Diversity Pattern And Density of Trees To Improve The Conservation of Species
}

Uzair Aslam Bhatti ( $\sim$ uzairaslambhatti@hotmail.com )

Nanjing Normal University

Zhaoyuan Yu

Nanjing Normal University

Linwang Yuan

Nanjing Normal University

Luo Wen

Nanjing Normal University

Saqib Ali Nawaz

Hainan University

Arif Hussain Kaleri

Hainan University

\section{Research Article}

Keywords: Aboveground biomass of trees, types of roads, roadside trees, tree diversity, non-native trees

Posted Date: May 17th, 2021

DOI: https://doi.org/10.21203/rs.3.rs-398246/v1

License: (1) This work is licensed under a Creative Commons Attribution 4.0 International License.

Read Full License

Version of Record: A version of this preprint was published at Environmental Science and Pollution Research on October 7th, 2021. See the published version at https://doi.org/10.1007/s11356-021-16627y. 


\title{
Evaluating the impact of roads on the diversity pattern and density of trees to improve the conservation of species
}

\author{
Uzair Aslam Bhatti ${ }^{1}$, Zhaoyuan Yu ${ }^{1,2}$, Linwang Yuan ${ }^{1,2}$, Luo Wen ${ }^{1,2}$, Saqib \\ Ali Nawaz ${ }^{3}$, Arif Hussain Kaleri ${ }^{3}$ \\ ${ }^{1}$ School of Geography, Nanjing Normal University, Nanjing 210014, P.R China \\ ${ }^{2}$ Key Laboratory of Virtual Geographic Environment, Ministry of Education, Nanjing \\ Normal University, No. 1 Wenyuan Road, Nanjing, China \\ ${ }^{3}$ Hainan University, Haikou, Hainan 570208,
}

correspondence; Uzair Aslam Bhatti (uzairaslambhatti@hotmail.com)

\begin{abstract}
:
Roads have a great impact on the structure and functioning of the diversity pattern in an ecological environment and play the role of altering biotic and abiotic factors. Clusters of plants grow along the roadside due to the interplay between the arrival of propagule and seedling establishment, which depends on the road's specifications, land pattern, and road administration and protection practices. It is very important to study the diversity pattern in a metropolitan city to improve the ecological environment. Karachi is one of the world's largest and fastest-growing metropolitan cities; however, little is known about the urban forest of the area. In Karachi, which is in the province of Sindh, Pakistan, roadside trees along various road types (e.g., wide, medium and narrow roads) have been studied. Based on a field study, various measures of diversity were utilized to investigate the diversity of tree species on different types of paths. A total of 180 plots, divided into three primary road groups, were surveyed. The highest quantity of tree biomass per unit area was found on wide roads, followed by medium roads. On narrow roads, the least biomass was detected. A single species or a limited number of species dominated the diversity of species. Conocarpus erectus was the most dominant nonnative species along all types of roads, followed by the species Guaiacum officinale. A total of 76 species (32 non-native and 44 native) that were selectively spread along the roadsides of the city were studied. There was a significant difference in phylogenetic diversity (PD), phylogenetic mean pairwise distance (MPD) and phylogenetic mean nearest taxon distance (MNTD) between wide, medium, and narrow roads. Management practices have a significant positive correlation with diversity indices. Our study identified patterns of diversity in roadside trees in Karachi. It provided the basis for future plant conservation planning, such as the conservation of plant species, the maintenance of plant habitats, and the coordination of plant management in Karachi.
\end{abstract}

Keywords: Aboveground biomass of trees; types of roads; roadside trees; tree diversity; nonnative trees

\section{Introduction}


Plant diversity is an important part of urban green space. It reflects the composition of a city's green space structure, urban diversity pattern and management level, and occupies an extremely important position in the entire urban ecological system[1]. The number and configuration of plant species directly affect the ecology of greening function and landscape effect[2]. Moreover, roadside plants reflect the characteristics of the geographical environment to a certain extent, and even become one of the characteristic signs of the city [3].

The structure and role of the urban natural ecological system (e.g., energy conversion, road building, material distribution, food chain, environmental purification) are closely linked to urban biodiversity[4]. In recent years, urban biodiversity conservation has achieved remarkable results; however, some countries have not paid enough attention to biodiversity conservation, and there has been insufficient native species protection and utilization [5]. There are many reasons for the huge loss of biodiversity in urban areas, which is causing a gradual change in the diversity patterns. Among them, the extinction of species caused by habitat destruction and degradation of habitat quality is due to the urban development by man and the continuous development of the ecosystem. Increasing the urban greening may cause a decrease in the temperature and an increase in the biodiversity pattern across the area [6].

Roadside tree planning in urban systems is playing a vital role since roadside trees act as local biodiversity reservoirs and reduce the pollution of the atmosphere by having a carbon stock [7]. The roadside ecosystem has significant importance because of its involvement in the diversity patterns of the biological life. Various studies have concluded that the ecosystem along the roadside is novel and unique [8][9]. Over the last few years, the construction of roads has increased significantly because of the economic growth of countries and the increase in urbanization, which causes new surfaces in different landscapes. Therefore, the soil patterns along the roadside are gradually changing, resulting in a change in plants' diversity patterns [10]. Roads and highways are an important infrastructure of the national economy, and the gradually increasing density of the highway network is the foundation for sustainable economic and social development. However, continuous construction and maintenance of roads causes the abiotic conditions of the system to change the physical and chemical environment of the surrounding area [11]. The construction of multi-lane and long roads and the wide distribution of resources in nature reserves will inevitably affect the ecology of nature reserves and change the living environment of animals in nature reserves.

The original topography and the continuity of the original structure have been altered due to the huge volume of urbanization and excavation, resulting in a variety of environmental issues, such as soil degradation, environmental contamination, habitat loss, and changes in the original river system, causing air pollution and noise pollution. The environmental role of road greening is reflected in the mitigation of the environmental effect of road building on the local area, such as dust collection and noise avoidance, air purification, water and soil protection, road temperature control, and biodiversity preservation along the road [12]. The 
greening of urban roads is designed according to the form of the road, and therefore it generally has linear characteristics. From this perspective, the greening of urban roads needs to be extended according to the actual needs of the road. Moreover, the planted varieties are diverse and have strong temporality. These varieties have different characteristics in different seasons. Therefore, the landscape of the entire city will also have seasonal changes, and the streetscape landscape effect is better [13].

The rise of cities led to the decline of plants. In today's cities, the original vegetation has disappeared, and the existing green vegetation is almost secondary. Due to the decline of the urban natural environment, the number of urban plants has decreased, and the diversity of species is extremely less. The plants next to houses, roadsides, artificial gardens, and parks are mainly cultivated and introduced, while the number of wild plants and native tree species is greatly reduced. As a result of natural disasters and man-made destruction, the living space of urban plants is smaller, and the threats they face are greater [14].

Simultaneously, the rise of cities has also caused the decline of wildlife. The survival of large animals relies on forests and wilderness. However, forests have disppeared around cities, and the wilderness is also occupied by humans, causing large animals to withdraw from urban areas. Modern urban animals include birds, urban insects, and livestock and poultry [15]. Due to the intensification of urbanization, the spatial heterogeneity of the urban environment has decreased, resulting in a decrease in the types of urban birds and a change in their composition, forming a relatively simple community of a few dominant species. These dominant species, such as house swallows, house martins, and sparrows, are only birds that utilize to artificially constructed nests. Another study reveals the important fact that with the gradual decrease in urban biological species, leads to a decline in biodiversity [16].

Roadsides create new opportunities for the relationship between different species and, in some cases, are helpful in providing segmented ecosystems for different types of plants that have different growth patterns [17]. The age of the road provides significant information related to the plantation and habitat along the roadside. A study has indicated that the native species are mostly found along the roadside of the youngest roads, while invasive species are mostly found close to old roads [18]. Only a few studies have focused on the temporal patterns of plant diversity along the roadside and the conditions of vegetation on these fragments. However, road age is not the only significant factor in the appearance of invasive species, as transportation is also a facilitator for the invasive species and causes them to spread out along the roadside [19]. Many studies have concluded that the ecosystem damage and transfer of invasive species along the roadside is due to the transportation [20][21].

With the continuous improvement of people's living standards, people have higher requirements for the environment. As an important part of urban infrastructure construction, the construction of urban roads has also received much attention. Moreover, to improve the quality of urban road construction, it is necessary to consider road landscape design and optimize plant species. Only in this way can we effectively change the ecological environment 
of the city and create a wonderful visual experience for people's daily travel. As mentioned above, many studies have focused on the diversity of roadside plants and animals; however, few studies have focused on the analysis of the patterns of diversity along the roadside. This study focuses on the analysis of the biodiversity patterns along the roadside and highlights the changes in the diversity patterns of plants. Therefore, this article investigates the composition and configuration of plant species along the main streets of the metropolitan city Karachi in Pakistan, which will help in improving the quality of the diversity patterns and ecological impact of the city.

\section{Material and Methods}

\section{Study area:}

We selected the metropolitan city Karachi, which is the most populous city in Pakistan and the sixth-largest city in the world [22]. The reasons for selecting this city are the continuous development of roads and the implementation of new projects for underpasses under bridges. This study highlights the significance of diversity patterns for the government for planning the roadside tree species. Karachi is located at $24045^{\prime} \mathrm{N}$ to $25037^{\prime} \mathrm{N}$ and $66042^{\prime} \mathrm{E}$ to $67 \mathrm{o} 34^{\prime} \mathrm{E}$ along the coast of the Arabian Sea (Figure 1) and it is eight meters above sea level [23]. The weather of Karachi is warm in summer and moderate in winter. In the summer, the temperature is between $25 \mathrm{oC}$ and $35 \mathrm{oC}$, and there is average rainfall. The winter is from the end of November to the beginning of February, and the daily average temperature is between $16 \mathrm{oC}$ and $21 \mathrm{oC}$. The winter is mostly dry, while the summer is mostly wet with high humidity. According to the 2020 world population survey, around 16 million people were living in the city, which covers an area of 3,580 km2 (Karachi Metropolitan Corporation, 2020). There are seven districts in Karachi (Central District, East District, West District, Korangi District, South District, Malir District, and Kemari District), and the annual population increase is estimated to be $6 \%$. This study examines the diversity pattern, composition, tree density, and taxonomic diversity of the roadside tree community. Some of the famous and long-distance roads are I. I. Chundrigar Road $(2.2 \mathrm{~km})$, M. A. Jinnah Road $(6.1 \mathrm{~km})$, Napier Road $(1.6 \mathrm{~km})$, Zaibunnisa Street $(1.1 \mathrm{~km})$, Shahrah-e-Faisal $(18.0 \mathrm{~km})$, Rashid Minhas Road (3.0 km), New Muhammad Ali Jinnah Road (6.1 km), and Nishtar Road $(5.6 \mathrm{~km})$. The different road routes across Karachi are shown in Figure 2. 


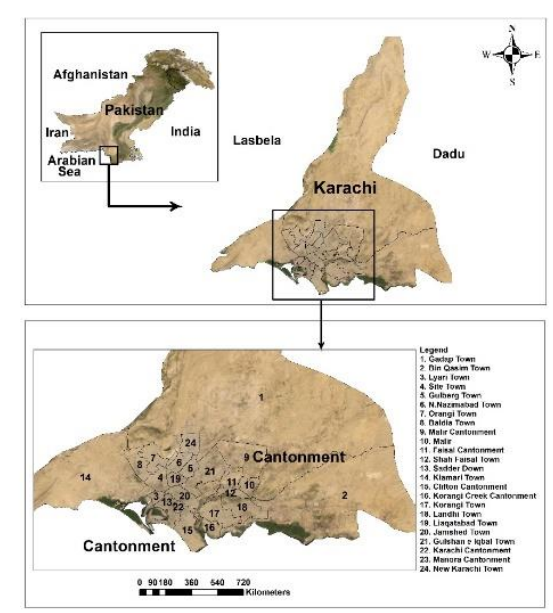

Figure 1: Location of towns in Karachi

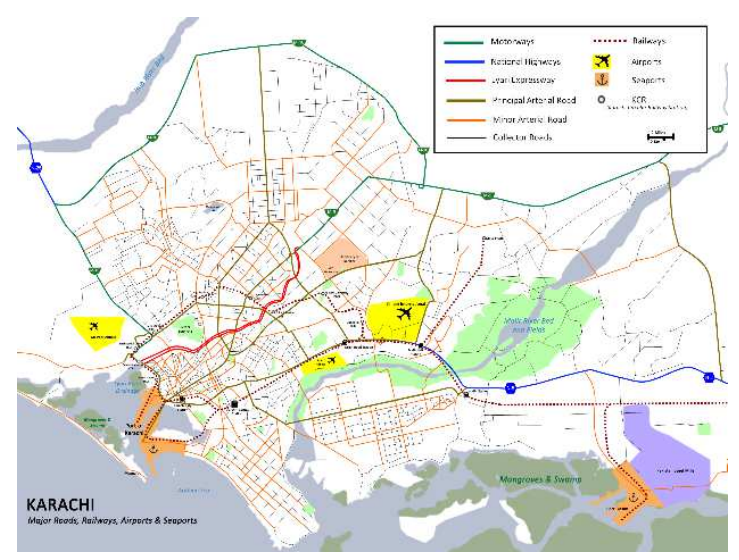

Figure 2: Road map of Karachi

\section{Data collection:}

To examine the diversity pattern along the roads, categories of roads are divided into wide (24 $\mathrm{m}$ or wider), medium (12 $\mathrm{m}$ to $24 \mathrm{~m}$ wide) and narrow (less than $12 \mathrm{~m}$ wide) roads [24]. The large roads of Karachi are known as the main roads and are bigger in scale than other road types. The linking roads between these large roads are medium roads. Usually, narrow roads are narrower than these two types. Departments of urban management oversee all road types and are responsible for planting trees. However, the pathways are near homes on small roads, and local people are also responsible for planting and caring for trees.

The sampling plots were chosen with the aid of Google Earth (https://www.google.com/earth/). On each lane, a sampling plot of $1 \mathrm{~km} \times 100 \mathrm{~m}$ is randomly used. The attribute lines are the width of each lane on each side of the road. On all types of roads, a total of 180 plots have been measured; each type of road has equivalent parcels. The key details calculated at the point of sampling are the name of the species of the tree, the number of branches, the diameter $(\mathrm{cm})$, the height $(\mathrm{cm})$, and the width of the crown of each roadside tree [25]. The strength of the management of each type of road was ascertained in interviews with maintenance staff and, if possible, local people. 


\section{Data Analysis:}

\section{Species diversity data}

To identify the species diversity in the plant population, the plant species diversity index was used as the most simple and succinct attribute, and the stability index was used to assess ecosystem stability [26]. Biodiversity can be quantified in many ways, and there are two major factors: richness (richness) and uniformity (evenness). Species richness does not consider conceptually how many individuals (in the sample) each species has. It gives the same weight to a species with a small number of individuals as a species with a large number of individuals. Uniformity refers to the relative abundance of different species (abundance), which complements each other and makes up. Diversity increases with the increase in species richness and uniformity [27]. The Simpson Diversity Index takes into account both richness and uniformity [28]. We used indices of species diversity from Simpson and Pielou (1966). The computational formulas are clarified below.

1. Richness of species (S) refers to the number of species of trees in each systemic urban unit.

2. The Simpson Diversity Index (D) corresponds to the possibility that two consecutive samples of a population that belong to the same species derive the corresponding number of individuals:

$$
\mathrm{D}=1-\sum_{i=1}^{n} P i^{2} P_{i}^{2}=\frac{\mathrm{n}_{i} \llbracket n_{i}-1 \rrbracket}{\mathrm{N} \llbracket \mathrm{N}-1 \rrbracket}
$$

This reflects the probability that two individuals are randomly selected from the same sample, and the two individuals are from the same class. The value of $\mathrm{N}$ is between 0 and 1 , where 0 means unlimited diversity, and 1 means no diversity; that is, the larger the $\mathrm{D}$ value, the lower the diversity.

3. The Pielou evenness index $(\mathrm{J})$ applies to the distribution in a group or society of the number of individuals:

$$
\mathrm{J}_{\mathrm{e}}=\frac{H_{\theta}^{r}}{H_{\max }^{r}}(2)
$$






Figure 3. Diversity indices for different tree types

Table 1. Frequency of roadside tree management variables per year

\begin{tabular}{lllll}
\hline Road types & Trimming & Fertilization & Cleaning & Watering \\
\hline Wide & $4.12 \pm 3.42$ & $2.23 \pm 1.45$ & $120.33 \pm 65.12$ & $133.95 \pm 112.32$ \\
Medium & $3.32 \pm 2.21$ & $1.88 \pm 1.10$ & $98.24 \pm 47.48$ & $93.34 \pm 67.54$ \\
Narrow & $1.23 \pm 1.01$ & $0.82 \pm 0.41$ & $28.53 \pm 21.67$ & $32.57 \pm 22.65$ \\
\hline
\end{tabular}

The value of Pielou's evenness lies between 0 (no evenness) and 1 (complete evenness).

Calculation of aboveground tree biomass:

Xue (2016) summarized a vast volume of data and used the model-fitting approach for Haikou's tree biomass to estimate and synthesize the following formula. We used it to quantify the biomass of the urban functional units of the aboveground trees:

AGB: Aboveground biomass of trees ( $\mathrm{g}$ )

DBH: Diameter at breast height $(\mathrm{cm})$

Height: Tree height $(\mathrm{cm})$

Wood density: wood density $(\mathrm{g} / \mathrm{cm} 3)$

The wood density of every species was derived from the TRY trait database (https://www.try-db.org/TryWeb/Home.php).

Taxonomic and phylogenetic diversity: 
For each map, we also estimated the number of species, mean phylogenetic distance (MPD), mean nearest taxon distance (MNTD), and phylogenetic diversity (PD). Over millions of years, PD is the sum of evolutionary history [29]. The average distance between an individual and the most closely connected (non-conspecific) individual is the MNTD. The MNTD in terminal branches is influenced by phylogenetic distance [30].

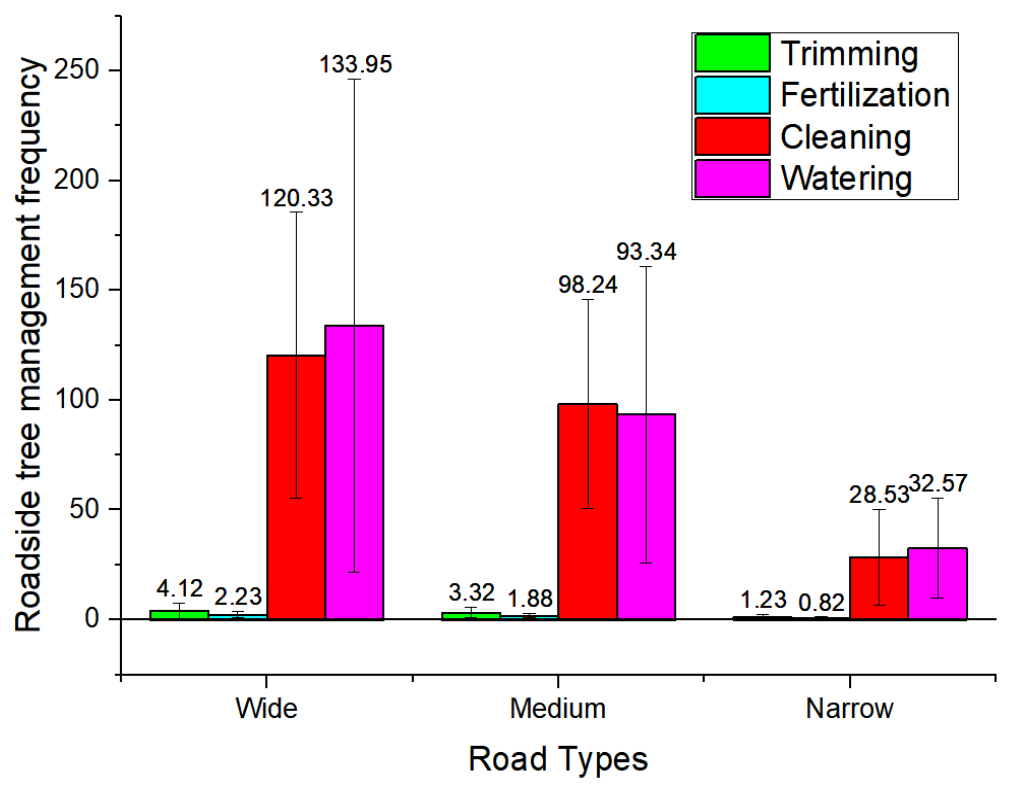

Figure 4. Roadside tree management activity

\section{Results}

Along wide roads, where the average aboveground biomass was $4.33 \mathrm{~kg} / \mathrm{m} 2$, much of the aboveground biomass of trees per unit area was found. The lowest tree biomass per unit area was $3.20 \mathrm{~kg} / \mathrm{m} 2$ along narrow roads. The second-lowest tree biomass per unit area was 3.50 $\mathrm{kg} / \mathrm{m} 2$ along medium roads (Figure 3 ). Moreover, the quantity of aboveground biomass per unit area of roadside trees in the city was significantly different. Overall, lower indices of species richness and diversity were observed. The range of species richness was 4.27-2.44, the range of the Simpson Diversity Index was 0.62-0.32, and the range of Pielou's evenness index was 0.31-0.26. Maximum richness and diversity were observed along wide roads, followed by medium roads and then narrow roads (Figure 3).

Conocarpus erectus had the largest number of trees and was followed by Guaiacum officinale. The native species Azadirachta indica had the largest number of trees, followed by Ficus virens. Overall, 32 non-native and 44 native specimens were found. On all path types, nonnative species accounted for $79.16 \%$ and native species accounted for $20.84 \%$ of the tree 
population. The flowers of common species of non-native trees observed in the region are shown in Figure 5. The non-native Conocarpus erectus constituted $61.87 \%$ of the total tree population, and it was followed by Guaiacum officinale with $9.02 \%$. The native Azadirachta indica accounted for $8.51 \%$ of the entire tree population, and it was followed by Ficus virens with $2.47 \%$. The relative distribution of the non-native species was greater than that of the native species in the field under study. Wide roads and medium roads have optimum maintenance activities (Figure 4 and Table 1). The dominant species along all types of roads was Conocarpus erectus. Furthermore, 14 indigenous tree species are at high risk (Table 4 and Table 5).

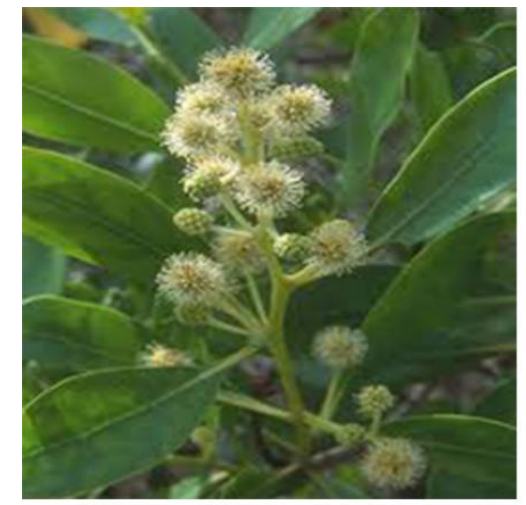

Conocarpus erectus

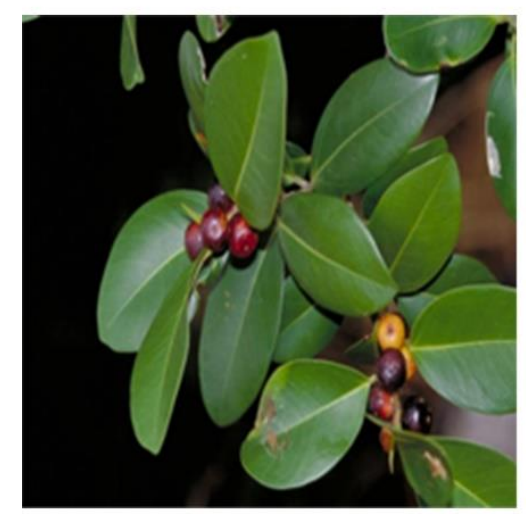

Ficus microcarpa

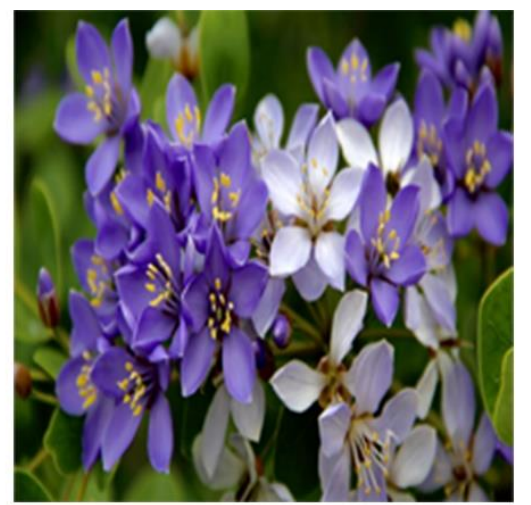

Guaiacum officinale

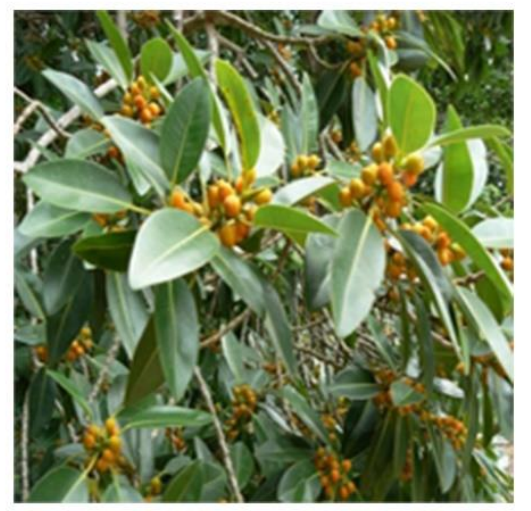

Ficus rubiginosa

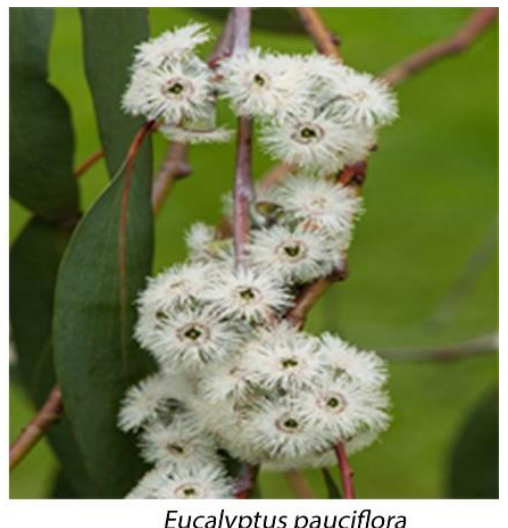

Eucalyptus pauciflora

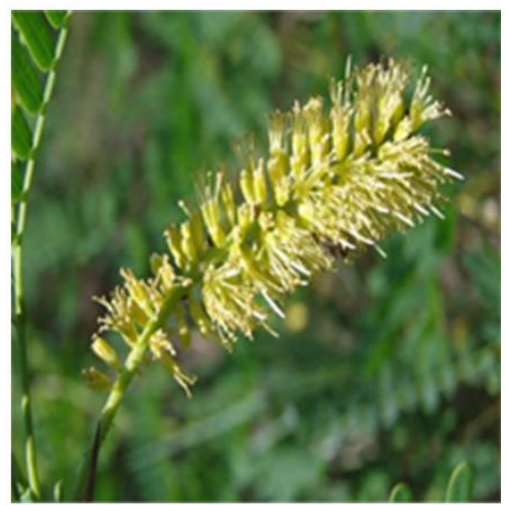

Prosopis juliflora

Figure 5. Flowers of common non-native trees species in Karachi

The study found that the PD, MPD and MNTD of non-native tree species were higher than those of native tree species. The PD, MPD and MNTD of wide roads were higher than those of medium and narrow roads for non-native and native tree species (Table 2). Management practices had a significant positive correlation with the indices of diversity (Table 3 ). 
Table 2: Mean value of PD, MPD and MNTD of three road types in Karachi

\begin{tabular}{lllllll}
\hline Road types & Non-native PD & Native PD & Non-native MPD & Native MPD & Non-native MNTD & Native MNTD \\
\hline Wide & $1366.51 \pm 345.88$ & $549.75 \pm 146.86$ & $297.41 \pm 34.50$ & $151.77 \pm 35.97$ & $145.16 \pm 35.68$ & $125.81 \pm 44.12$ \\
Medium & $1086.57 \pm 265.88$ & $463.59 \pm 122.36$ & $195.57 \pm 29.29$ & $134.08 \pm 35.59$ & $127.01 \pm 28.77$ & $120.40 \pm 34.63$ \\
Narrow & $836.53 \pm 165.88$ & $320.87 \pm 104.36$ & $184.23 \pm 31.99$ & $126.68 \pm 32.76$ & $110.45 \pm 33.88$ & $109.82 \pm 24.69$
\end{tabular}

Note: PD - Faith's phylogenetic diversity; MPD - phylogenetic mean pairwise distance; and MNTD - phylogenetic mean nearest taxon distance

Table 3: The correlation between the management variable and the diversity index also includes biomass

\begin{tabular}{|c|c|c|c|c|c|c|c|c|c|c|}
\hline $\begin{array}{l}\text { Management } \\
\text { variables }\end{array}$ & $\begin{array}{l}\text { Species } \\
\text { diversity } \\
\text { (S) }\end{array}$ & $\begin{array}{l}\text { Simpson } \\
\text { Diversity } \\
\text { Index (D) }\end{array}$ & $\begin{array}{l}\text { Pielou's } \\
\text { evenness } \\
\text { index }(\mathrm{J})\end{array}$ & Biomass & Non-native PD & Native PD & Non-native MPD & Native MPD & Non-native MNTD & Native MNTD \\
\hline Trimming & $.954 * *$ & $.998 * *$ & $.997 * *$ & $.869 * *$ & $.960 * *$ & $.994 * *$ & $.775^{*}$ & $.885^{* *}$ & $.961 * *$ & $.998 * *$ \\
\hline Fertilization & $.944 * *$ & $.996 * *$ & $.999 * *$ & $.854 * *$ & $.951 * *$ & $.990 * *$ & $.755^{*}$ & $.870 * *$ & $.953 * *$ & $.995^{* *}$ \\
\hline Cleaning & $.941 * *$ & $.995^{* *}$ & $.999 * *$ & $.850 * *$ & $.948 * *$ & $.989 * *$ & $.749 *$ & $.866^{* *}$ & $.950 * *$ & $.994 * *$ \\
\hline Watering & $.986 * *$ & $.997 * *$ & $.976 * *$ & $.929 * *$ & $.989 * *$ & $1.000 * *$ & $.854 * *$ & $.940 * *$ & $.990 * *$ & $.998 * *$ \\
\hline
\end{tabular}

** Correlation is significant at the 0.01 level. * Correlation is significant at the 0.05 level. 
Table 4: Number of trees of native species

\begin{tabular}{|c|c|c|}
\hline Family & Species name & Number of trees \\
\hline Mimosaceae & Acacia nilotica & 1 \\
\hline Mimosaceae & Acacia Senegal & 1 \\
\hline Primulaceae & Aegiceras corniculata & 1 \\
\hline Rutaceae & Aegle marmelos & 7 \\
\hline Fabaceae & Albizia julibrissin & 492 \\
\hline Fabaceae & Albizia lebbeck & 191 \\
\hline Apocynaceae & Alstonia scholaris & 243 \\
\hline Meliaceae & Azadirachta indica & 4074 \\
\hline Malvaceae & Bombax ceiba & 22 \\
\hline Capparidaceae & Capparis decidua & 1 \\
\hline Fabaceae & Cassia fistula & 73 \\
\hline Malvaceae & Ceiba pentandra & 22 \\
\hline Arecaceae & Cocos nucifera & 361 \\
\hline Boraginaceae & Cordia gharaf & 14 \\
\hline Boraginaceae & Cordia macheodii & 7 \\
\hline Boraginaceae & Cordia myxa & 66 \\
\hline Capparaceae & Crateva adansonii & 198 \\
\hline Fabaceae & Dalbergia sissoo & 22 \\
\hline Poaceae & Dendrocalamus stricta & 367 \\
\hline Fabaceae & Erythrina suberosa & 102 \\
\hline Euphorbiaceae & Euphorbia caducifolia & 1 \\
\hline Euphorbiaceae & Euphorbia tirucalli & 1 \\
\hline Moraceae & Ficus amplissima & 29 \\
\hline Moraceae & Ficus benghalensis & 257 \\
\hline Moraceae & Ficus racemosa & 110 \\
\hline Moraceae & Ficus religiosa & 404 \\
\hline Moraceae & Ficus rumphii & 29 \\
\hline Moraceae & Ficus virens & 1184 \\
\hline Meliaceae & Melia azedarach & 147 \\
\hline Mimosaceae & Mimosa hamata & 1 \\
\hline Moringaceae & Moringa oleifera & 250 \\
\hline Palmae & Nannorphs ritichiana & 1 \\
\hline Arecaceae & Phoenix dactylifera & 560 \\
\hline Mimosaceae & Prosopis cineraria & 1 \\
\hline Lythraceae & Punica granutum & 8 \\
\hline Salvadoraceae & Salvadora oleoides & 1 \\
\hline Salvadoraceae & Salvadora persica & 1 \\
\hline Tamaricaceae & Tamarix aphylla & 1 \\
\hline Bignoniaceae & Tecomella undulata & 1 \\
\hline Combretaceae & Terminalia catappa & 147 \\
\hline Malvaceae & Thespesia pupulnea & 117 \\
\hline Rhamnaceae & Ziziphus jujuba & 317 \\
\hline
\end{tabular}


Table 5: Number of trees of non-native species

\begin{tabular}{|c|c|c|}
\hline Family & Species name & Number of trees \\
\hline Araucariaceae & Araucaria cunninghamii & 7 \\
\hline Caricaceae & Carica papaya & 6 \\
\hline Fabaceae & Cassia siamea & 95 \\
\hline Casuarinaceae & Casuarina equisetifolia & 58 \\
\hline Combretaceae & Conocarpus erectus & 29589 \\
\hline Boraginaceae & Cordia sebestena & 14 \\
\hline Fabaceae & Delonix regia & 29 \\
\hline Myrtaceae & Eucalyptus pauciflora & 1706 \\
\hline Bignoniaceae & Fernandoa adenophylla & 22 \\
\hline Moraceae & Ficus benjamina & 51 \\
\hline Moraceae & Ficus elastica & 80 \\
\hline Moraceae & Ficus lyrata & 7 \\
\hline Moraceae & Ficus microcarpa & 501 \\
\hline Moraceae & Ficus rubiginosa & 382 \\
\hline Zygophylaceae & Guaiacum officinale & 4318 \\
\hline Fabaceae & Leucaena leucocephala & 139 \\
\hline Arecaceae & Livistona chinensis & 23 \\
\hline Anacardiaceae & Mangifera indica & 30 \\
\hline Sapotaceae & Manilkara zapota & 8 \\
\hline Bignoniaceae & Millingtonia hortensis & 14 \\
\hline Moraceae & Morus nigra & 14 \\
\hline Apocynaceae & Nerium oleander & 8 \\
\hline Fabaceae & Parkinsonia aculeata & 88 \\
\hline Fabaceae & Peltophorum pterocarpum & 87 \\
\hline Fabaceae & Pithecellobium dulce & 66 \\
\hline Annonaceae & Polyalthia longifolia & 67 \\
\hline Fabaceae & Prosopis juliflora & 242 \\
\hline Arecaceae & Roystonea regia & 96 \\
\hline Myrtaceae & Syzgium cumini & 22 \\
\hline Bignoniaceae & Tabebuia heterophylla & 51 \\
\hline Fabaceae & Tamarindus indica & 29 \\
\hline Arecaceae & Washingtonia robusta & 7 \\
\hline
\end{tabular}

\section{DISCUSSION}

Importance of roadside tree populations 
Different plant species have different patterns of diversity, which results in various growing varieties using roadsides as temporary or permanent habitats. In the last few years, numerous studies have documented how roadsides affect the distribution and dispersal of plant species; however, this study is focused on roadside diversity patterns in a metropolitan city, which attracts attention to diversity patterns in an ecological environment. Results showed the strong superiority of Conocarpus erectus along the roadsides of Karachi, followed by Guaiacum officinale (Tables 4 and 5). The non-native species accounted for $79.16 \%$ and the native species accounted for $20.84 \%$ of the tree communities along all road types, similar to results reported by [31]Shams et al. (2020). The diversity pattern of the roadside species in Karachi is similar to the structure of five American municipalities that, at the end of the 1980s, showed significant advantages for single species in their roadside tree communities [32]. Conversely, the prevalence of Conocarpus erectus is more important along all road types since the plant has been grown extensively in the past decade. The typical DBH of Conocarpus erectus is smaller than that of the tree community's native species. Upright trees with a large diameter were not commonly found along urban roads in the research. Conocarpus erectus is also a species with a medium DBH. Trees with a high DBH, recorded on a wide scale, are the major tree species on American urban paths. In comparison, they are much older than those in Karachi [32].

Roadside trees provide habitat and serve as dispersal routes for different types of plants, including threatened, expansive, weed and exotic species, which can disperse to the adjacent landscape and exert a negative impact on the environment. Alien species have been introduced in different projects for the development of the green environment by the government [31]. Usually, civilian agencies grow and care for road trees. Residents typically plant trees along the roads near their homes. This boosts the food access of other animals and decreases the monoculture. Residents generally grow Azadirachta indica due to the preference for native species. Multiple species are more immune to viruses, predators, and infections than a single species [31].

Moreover, planting a single species requires lower maintenance costs. However, huge costs for its elimination and reconstruction can be sustained within a few years due to disease infection or aging of the dominant species [32]. Planting road trees alone has caused significant damage in various metropolitan regions of the world. For example, millions of American elm trees (Ulmus americana) extensively planted along North American roads have been destroyed due to Dutch elm disease (Ophiostoma ulmi). The risk of damage caused by 
rodents, viruses, insects, and environmental changes is reduced by increased taxonomic diversity in roadside tree populations [33].

The extensive cultivation of exotic species in Karachi is another area of concern. Alien species are less suitable for agriculture in urban areas than native species . Furthermore, native roadside trees have more range and density than tropical trees [34]. Conversely, the occurrence of mistletoe in foreign species is even greater relative to native species [35]. However, with the stability of the urban ecosystem, foreign and indigenous animals have the same ecological resources [36]. According to [37] report, the elimination of invasive species from urban forestry is generally not feasible, primarily due to the insufficient availability of native species to address the demand for ecological services in the harsh urban environment. In under developing urban areas, many invasive species have better ecological services than native species. Civilian organizations prefer to utilize alien species mainly because of their accelerated expansion; this is primarily due to the presence of government departments, thereby growing the proportion of coastal cities. It is worth recalling that this study found that species diversity was smaller along Karachi's roads than in 22 cities in the United States [32] and South Africa's Eastern Cape Province [38].

Variation of aboveground tree biomass in urban functional units:

Our analysis revealed that on large paths, the aboveground tree biomass per unit area significantly exceeded that of other urban functional units. This suggests that the density of species is high and/or the number of trees on wide roads per unit area is significant. The greening rate of this region is one explanation for the fluctuations in tree biomass along large roads. Via land-use adjustments, the trees used for natural resources will be preserved, and this positive pattern has been seen in many places [39]. Pike et al. [40] found that trees used for natural goods have been maintained for financial and decorative reasons on private property. The practical uses of urban greenspace for individuals are illustrated by urban inhabitants [41]. The superiority of species with desirable and emblematic characteristics was further illustrated by studies of trees in Hong Kong [42].

\section{Taxonomic diversity and PD:}

The PD, MPD and MNTD values of the trees were significantly different between wide, medium and narrow roads. The composition of the plants in Karachi has been influenced by changes in management frequency and type of road [43]. Human management and environmental factors have been closely linked to plant diversity [44]. Various applications of fertilizers, pests, and pathogen attacks that caused varying habitat conditions among the 
vegetation formations have led to different plant diversity patterns. Karachi has many important tourist attractions that have also impacted the diversity of the plants. Mangubhai et al. (2020) [45] found that, particularly in the coastal regions, tourism-related practices contribute to biodiversity loss. The number of ornamental plants on the study site is high because of tourism. For beauty and leisure, native and invasive plants were introduced at the same time. On the large paths, PD, MPD and MNTD values were the highest. This showed that plant diversity was high; the phylogenetic structure was over-dispersed due to the enormous phylogenetic gap between plants. Fewer management practices were implemented along the narrow roads. Roadside trees here were planted decades ago and added to the plant diversity. On the narrow roads, PD, MPD and MNTD values were the lowest, indicating that the phylogenetic structure of the species is clustered, and the diversity of the plants is significantly lower. These results may have been due to the fact that narrow roads have a more stressful environment for plants due to human activities. Since species sharing traits along near-phylogenetic lines may have similar environmental reactions, extreme environmental conditions are likely to be associated with species, leading to low species resources and low PD. PD may be related to the species richness distribution pattern along narrow roads. In a population, lower species diversity contributes to reduced PD [46].

The effects of the natural ecology and environment along the roadside construction also have a negative impact. The damage to the radiation and surface soil along the line is one of the most significant and intuitive effects [47]. The initial stage of roadside construction will completely clear the resettlement and topsoil within the land occupation boundary. This is the most important stage of resettlement and topsoil destruction, which will cause a large amount of biomass loss and soil erosion along the line. The large area of exposed ground formed by the excavation of highway construction is not a difficulty in the reconstruction and restoration of roadside construction and will adversely affect the stability of the regional ecosystem in the future [48]. The local plants with parasites distributed along the highway are characterized by good landscape integration, which is of great significance for maintaining the stability of the regional ecosystem. The topsoil along the road is also a type of scarce, non-renewable, and important ecological soil surface in nature. The basic resources of value, including the cultivated layer of cultivated land; the surface layer and humus layer of garden land, woodland, and grassland; and the content of organic matter, microorganisms, and local seeds, are most beneficial to the rapid restoration of soil fertility and plant growth. Radiation and topsoil along the highway are an important part of the regional ecosystem. Therefore, 
studying the characteristics of plant species' diversity patterns and soil environmental quality along the highway is of great significance for roadside environmental protection and green highway construction.

\section{CONCLUSION}

To assess the taxonomic and phylogenetic richness of roadside trees in Karachi, the capital of Sindh province, we utilized a variety of approaches. In our study site, the richness and composition of plants were significantly affected by road types. Our hypothesis that diversity is negatively correlated with road width is rejected, and our alternate hypothesis that diversity is positively correlated with road width is accepted. To enhance our knowledge of the ecological and evolutionary mechanisms that form plant diversity, which, in turn, is an integral property of ecosystems, research that incorporates various diversity metrics should be conducted. Management practices have a significant positive correlation with diversity indices. Our study revealed the link between diversity and the structure of the community. Although few species are dominant, it is vital to plant other species that are more eco-friendly and help in improving the ecological system. Effective roadside management is highly important to reduce the viability of exotic/weed populations while facilitating the presence of desirable species. Furthermore, other taxa should be introduced into urban tree communities with low species richness and diversity. Moreover, it is necessary to plant more endangered native species and provide all the critical facilities required to improve diversity. Invasive plants that have not been spread by humans should not be cultivated in towns. To create productive and balanced urban forests, trees with a high degree of taxonomic diversity must be spread equally along the roads. The tree population must not be governed by one or two species. In urban tree ecosystems, the proportion of any single species does not exceed 5\%. In Karachi, more than 50\% is constituted by one single species. Our research offers information that helps to control habitat protection and resources for the environment.

\section{Acknowledgements}

Special thanks to Zhaoyuan Yu for his valuable support in this investigation.

\section{Availability of data and material}

Not applicable.

\section{Code availability}

Not applicable

\section{Authors' contributions}

Uzair Aslam Bhatti was responsible for data collection ; zhaoyuan yu and linwang yuan did data analysis; Luo wen and Saqib Ali Nawaz wrote the manuscript and were involved in text 
corrections.Arif Hussain Kaleri proofread the paper. All the authors read and approved the final manuscript.

\section{Declarations}

\section{Ethics approval}

Not applicable.

\section{Consent to participate}

Not applicable.

\section{Consent for publication}

Not applicable.

\section{Conflicts of interest/competing interests}

The authors declare that there is no conflict of interest.

\section{REFERENCES}

[1] Aronson, M. F., Lepczyk, C. A., Evans, K. L., Goddard, M. A., Lerman, S. B., MacIvor, J. S., ... \& Vargo, T. Biodiversity in the city: key challenges for urban green space management. Frontiers in Ecology and the Environment, 15(4), 189-196. 2017.

[2] Hadley, A. S., \& Betts, M. G. The effects of landscape fragmentation on pollination dynamics: absence of evidence not evidence of absence. Biological Reviews, 87(3), 526-544. 2012.

[3] Yilmaz, H., \& Yilmaz. Use of native plants in landscape planning of roadside banks under extreme climatic conditions in eastern Anatolia, Turkey. International Journal of Biodiversity Science \& Management, 5(2), 102-113. H. 2009.

[4] Alberti, M., \& Marzluff, J. M. Ecological resilience in urban ecosystems: linking urban patterns to human and ecological functions. Urban ecosystems, 7(3), 241-265. 2004.

[5] Fors, D. The Native Species Protection Act: A Deceptively-Named Measure to Destroy the Endangered Species Act. Vill. Envtl. LJ, 29, 177. 2018.

[6] Masoudi, M., \& Tan, P. Y. Multi-year comparison of the effects of spatial pattern of urban green spaces on urban land surface temperature. Landscape and Urban Planning, 184, 44-58. 2019.

[7] Xing, Y., \& Brimblecombe, P. Trees and parks as "the lungs of cities". Urban Forestry \& Urban Greening, 48, 126552. 2020.

[8] Auestad, I., Rydgren, K., \& Austad, I. Near-natural methods promote restoration of species-rich grassland vegetation-revisiting a road verge trial after 9 years. Restoration Ecology, 24(3), 381-389. 2016. 
[9] Lázaro-Lobo, A., \& Ervin, G. N. A global examination on the differential impacts of roadsides on native vs. exotic and weedy plant species. Global Ecology and Conservation, 17, e00555. 2019.

[10] Jimenez, M. D., Ruiz-Capillas, P., Mola, I., Pérez-Corona, E., Casado, M. A., \& Balaguer, L. Soil development at the roadside: a case study of a novel ecosystem. Land Degradation \& Development, 24(6), 564-574. 2013.

[11] Trombulak, S. C., \& Frissell, C. A. Review of ecological effects of roads on terrestrial and aquatic communities. Conservation biology, 14(1), 18-30. 2000.

[12] Wu, L., Ye, K., Gong, P., \& Xing, J. Perceptions of governments towards mitigating the environmental impacts of expressway construction projects: A case of China. Journal of Cleaner Production, 236, 117704. 2019.

[13] Ignatieva, M., Stewart, G. H., \& Meurk, C. Planning and design of ecological networks in urban areas. Landscape and ecological engineering, 7(1), 17-25. 2011.

[14] Cuttelod, A., García, N., Malak, D. A., Temple, H. J., \& Katariya, V. The Mediterranean: a biodiversity hotspot under threat. Wildlife in a Changing World-an analysis of the 2008 IUCN Red List of Threatened Species, 89. 2009.

[15] Bradley, C. A., \& Altizer, S. Urbanization and the ecology of wildlife diseases. Trends in ecology \& evolution, 22(2), 95-102. 2007.

[16] $\mathrm{Hu}, \mathrm{X} ., \& \mathrm{Xu}, \mathrm{H} . \mathrm{A}$ new remote sensing index for assessing the spatial heterogeneity in urban ecological quality: A case from Fuzhou City, China. Ecological Indicators, 89, 11-21. 2018.

[17] Walsh, S. J., McCleary, A. L., Mena, C. F., Shao, Y., Tuttle, J. P., González, A., \& Atkinson, R. QuickBird and Hyperion data analysis of an invasive plant species in the Galapagos Islands of Ecuador: Implications for control and land use management. Remote Sensing of Environment, 112(5), 1927-1941. 2008.

[18] Spooner, P. G., \& Smallbone, L. Effects of road age on the structure of roadside vegetation in south-eastern Australia. Agriculture, Ecosystems \& Environment, 129(1-3), 57-64. 2009.

[19] Hansen, M. J., \& Clevenger, A. P. The influence of disturbance and habitat on the presence of non-native plant species along transport corridors. Biological conservation, 125(2), 249-259. 2005.

[20] Crowl, T. A., Crist, T. O., Parmenter, R. R., Belovsky, G., \& Lugo, A. E. The spread of invasive species and infectious disease as drivers of ecosystem change. Frontiers in Ecology and the Environment, 6(5), 238-246. 2008.

[21] Schwartz, M. W., Hoeksema, J. D., Gehring, C. A., Johnson, N. C., Klironomos, J. N., Abbott, L. K., \& Pringle, A. The promise and the potential consequences of the global transport of mycorrhizal fungal inoculum. Ecology letters, 9(5), 501-515. 2006. 
[22] Mehboob, A., \& Abbas, T. Evaluation of microbial quality of street food in Karachi City, Pakistan: An epidemiological study. Microbiology Research, 10(1), 1-7. 2019.

[23] Ahmed, F., \& Ulfat, I. Empirical models for the correlation of monthly average daily global solar radiation with hours of sunshine on a horizontal surface at Karachi, Pakistan. Turkish Journal of Physics, 28(5), 301-307. 2004.

[24] Nagendra, H., \& Gopal, D. Street trees in Bangalore: Density, diversity, composition and distribution. Urban forestry \& urban greening, 9(2), 129-137. 2010.

[25] Forman, R. T., Reineking, B., \& Hersperger, A. M. Road traffic and nearby grassland bird patterns in a suburbanizing landscape. Environmental management, 29(6), 782-800. 2002.

[26] Rad, J. E., Manthey, M., \& Mataji, A. Comparison of plant species diversity with different plant communities in deciduous forests. International Journal of Environmental Science \& Technology, 6(3), 389-394. 2009.

[27] Hurlbert, S. H. The nonconcept of species diversity: a critique and alternative parameters. Ecology, 52(4), 577-586. 1971.

[28] Simpson, E. H. Measurement of diversity. nature, 163(4148), 688-688. 1949.

[29] Cadotte, M. W., Jonathan Davies, T., Regetz, J., Kembel, S. W., Cleland, E., \& Oakley, T. H. Phylogenetic diversity metrics for ecological communities: integrating species richness, abundance and evolutionary history. Ecology letters, 13(1), 96-105. 2010

[30] Mazel, F., Davies, T. J., Gallien, L., Renaud, J., Groussin, M., Münkemüller, T., \& Thuiller, W. Influence of tree shape and evolutionary time-scale on phylogenetic diversity metrics. Ecography, 39(10), 913-920. 2016.

[31] Shams, Z. I., Shahid, M., Nadeem, Z., Naz, S., Raheel, D., Aftab, D., ... \& Roomi, M. S. Town socio-economic status and road width determine street tree density and diversity in Karachi, Pakistan. Urban Forestry \& Urban Greening, 47, 126473. 2020.

[32] McPherson, E. G., \& Rowntree, R. A. Using structural measures to compare twenty-two US street tree populations. Landscape Journal, 8(1), 13-23. 1989.

[33] Dukes, J. S., Pontius, J., Orwig, D., Garnas, J. R., Rodgers, V. L., Brazee, N., ... \& Ayres, M. Responses of insect pests, pathogens, and invasive plant species to climate change in the forests of northeastern North America: What can we predict? Canadian journal of forest research, 39(2), 231-248. 2009.

[34] Singh, H., Yadav, M., Kumar, N., Kumar, A., \& Kumar, M. Assessing adaptation and mitigation potential of roadside trees under the influence of vehicular emissions: A case study of Grevillea robusta and Mangifera indica planted in an urban city of India. Plos one, 15(1), e0227380. 2020. 
[35] Cocoletzi, E., Angeles, G., Briones, O., Ceccantini, G., \& Ornelas, J. F. The ecophysiology of a neotropical mistletoe depends on the leaf phenology of its tree hosts. American Journal of Botany, 107(9), 1225-1237. 2020.

[36] Zhang, M., Zhou, Y., Liu, X., \& Lu, Z. Ecological landscape regulation approaches in Xilingol, Inner Mongolia: an urban ecosystem services perspective. International Journal of Sustainable Development \& World Ecology, 24(5), 401-407. 2017.

[37] Sádlo, J., Vítková, M., Pergl, J., \& Pyšek, P. Towards site-specific management of invasive alien trees based on the assessment of their impacts: the case of Robinia pseudoacacia. NeoBiota, 35, 1. 2017.

[38] Gwedla, N., \& Shackleton, C. M. Population size and development history determine street tree distribution and composition within and between Eastern Cape towns, South Africa. Urban Forestry \& Urban Greening, 25, 11-18. 2017.

[39] Wang, W., Zhang, B., Xiao, L., Zhou, W., Wang, H., \& He, X. Decoupling forest characteristics and background conditions to explain urban-rural variations of multiple microclimate regulation from urban trees. PeerJ, 6, e5450. 2018.

[40] Pike, K., O’Herrin, K., Klimas, C., \& Vogt, J. Tree preservation during construction: An evaluation of a comprehensive municipal tree ordinance. Urban Forestry \& Urban Greening, 57, 126914. 2021.

[41] Song, Y., Chen, B., \& Kwan, M. P. How does urban expansion impact people's exposure to green environments? A comparative study of 290 Chinese cities. Journal of Cleaner Production, 246, 119018. 2020.

[42] Stange, M., Barrett, R. D., \& Hendry, A. P. The importance of genomic variation for biodiversity, ecosystems and people. Nature Reviews Genetics, 1-17. 2020 .

[43] Shaheen, H., Riffat, A., Salika, M., \& Firdous, S. S. Impacts of roads and trails on floral diversity and structure of Ganga-Choti forest in Kashmir Himalayas. Bosque, 39(1), 71-79. 2018.

[44] Chen, S., Wang, W., Xu, W., Wang, Y., Wan, H., Chen, D., ... \& Bai, Y. Plant diversity enhances productivity and soil carbon storage. Proceedings of the National Academy of Sciences, 115(16), 4027-4032. 2018.

[45] Mangubhai, S., Sykes, H., Manley, M., Vukikomoala, K., \& Beattie, M. Contributions of tourism-based Marine Conservation Agreements to natural resource management in Fiji. Ecological Economics, 171, 106607. 2020

[46] LaManna, J. A., Mangan, S. A., Alonso, A., Bourg, N. A., Brockelman, W. Y., Bunyavejchewin, S., ... \& Myers, J. A. Plant diversity increases with the strength of negative density dependence at the global scale. Science, 356(6345), 1389-1392. 2017. 
[47] Wang, M., Liu, Q., \& Pang, X. Evaluating ecological effects of roadside slope restoration techniques: A global meta-analysis. Journal of Environmental Management, 281, 111867. 2021.

[48] Wairiu, M. Land degradation and sustainable land management practices in Pacific Island Countries. Regional Environmental Change, 17(4), 1053-1064. 2017. 


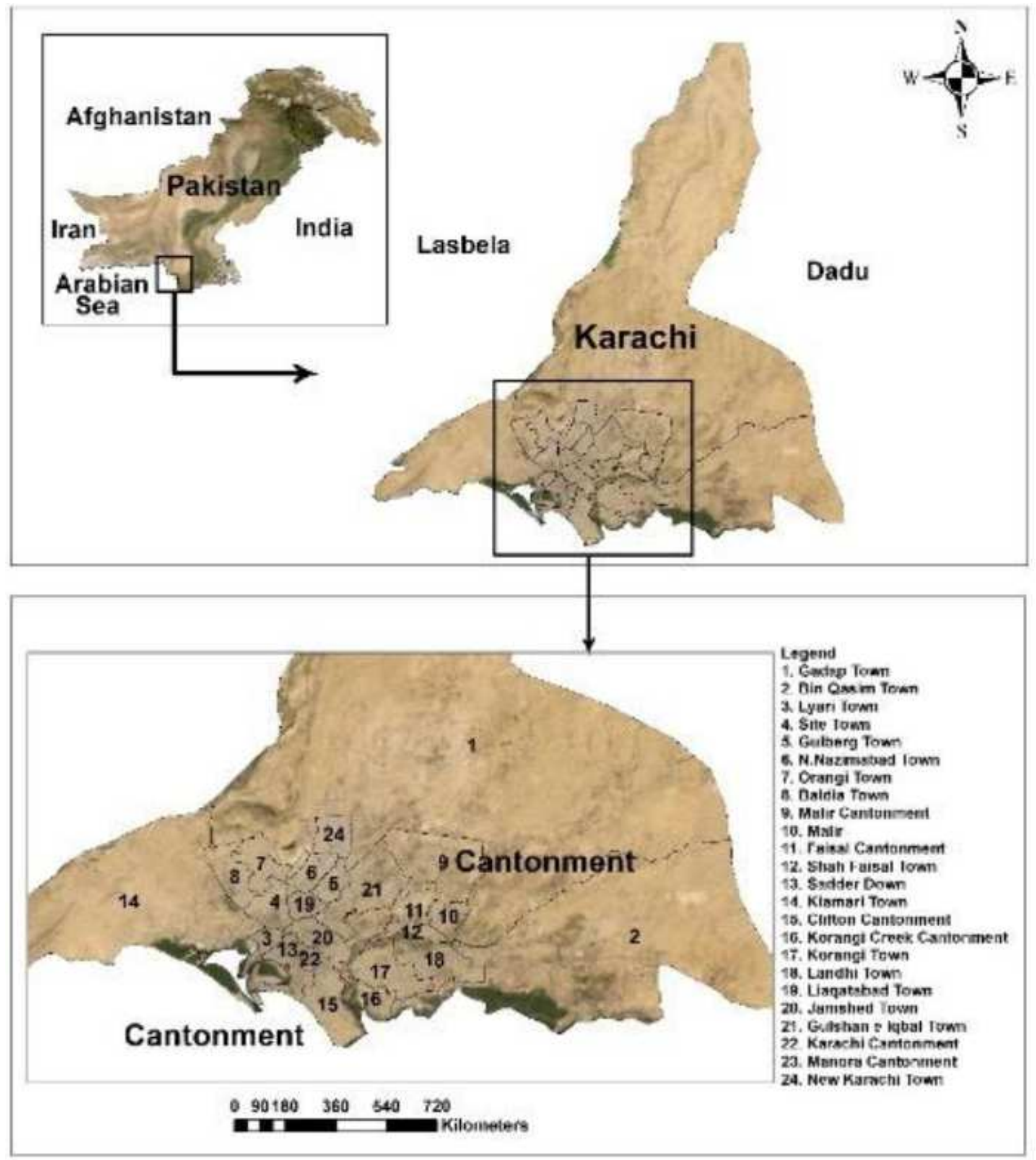

\section{Figure 1}

Location of towns in Karachi Note: The designations employed and the presentation of the material on this map do not imply the expression of any opinion whatsoever on the part of Research Square 
concerning the legal status of any country, territory, city or area or of its authorities, or concerning the delimitation of its frontiers or boundaries. This map has been provided by the authors.

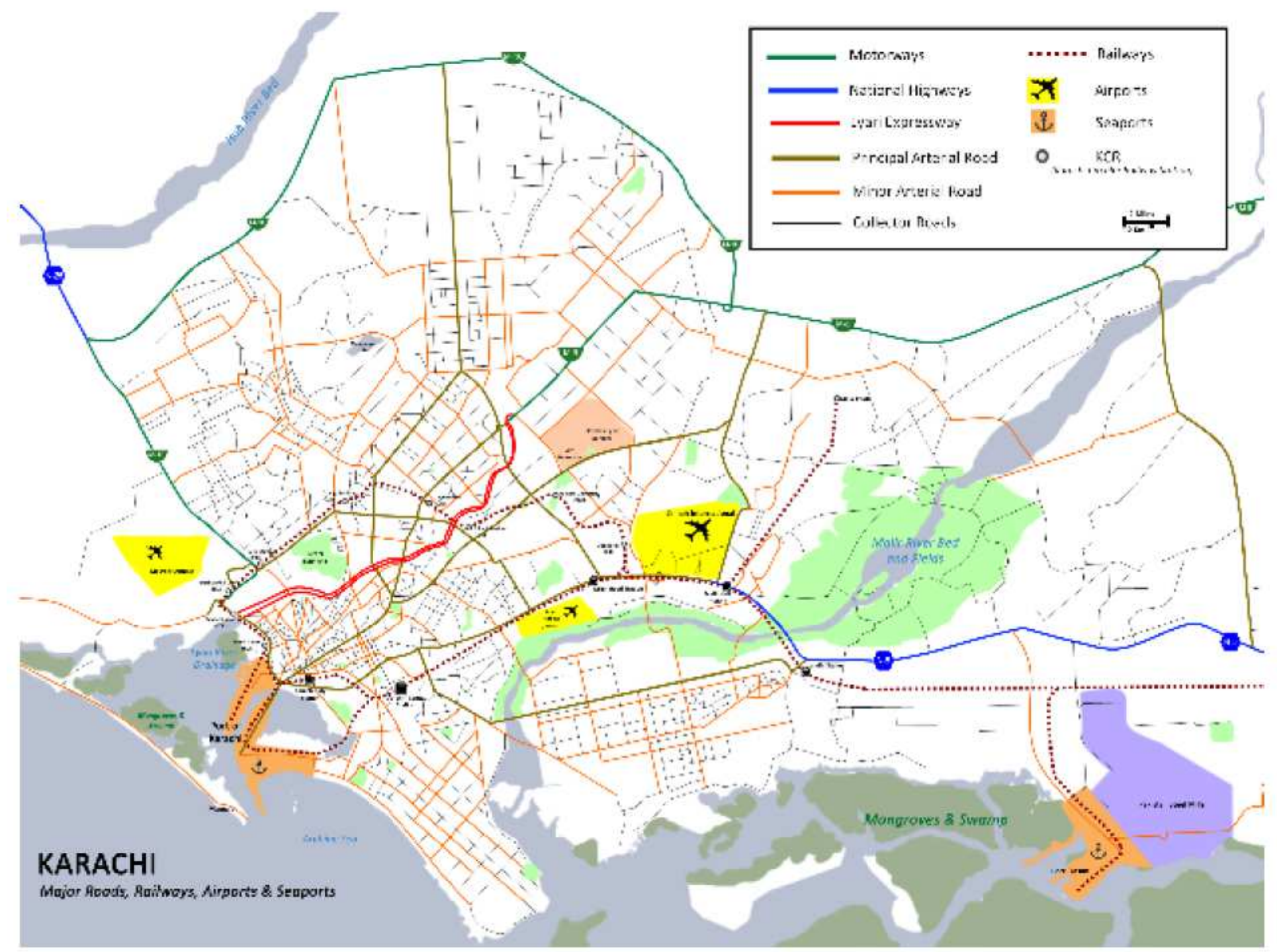

\section{Figure 2}

Road map of Karachi Note: The designations employed and the presentation of the material on this map do not imply the expression of any opinion whatsoever on the part of Research Square concerning the legal status of any country, territory, city or area or of its authorities, or concerning the delimitation of its frontiers or boundaries. This map has been provided by the authors. 


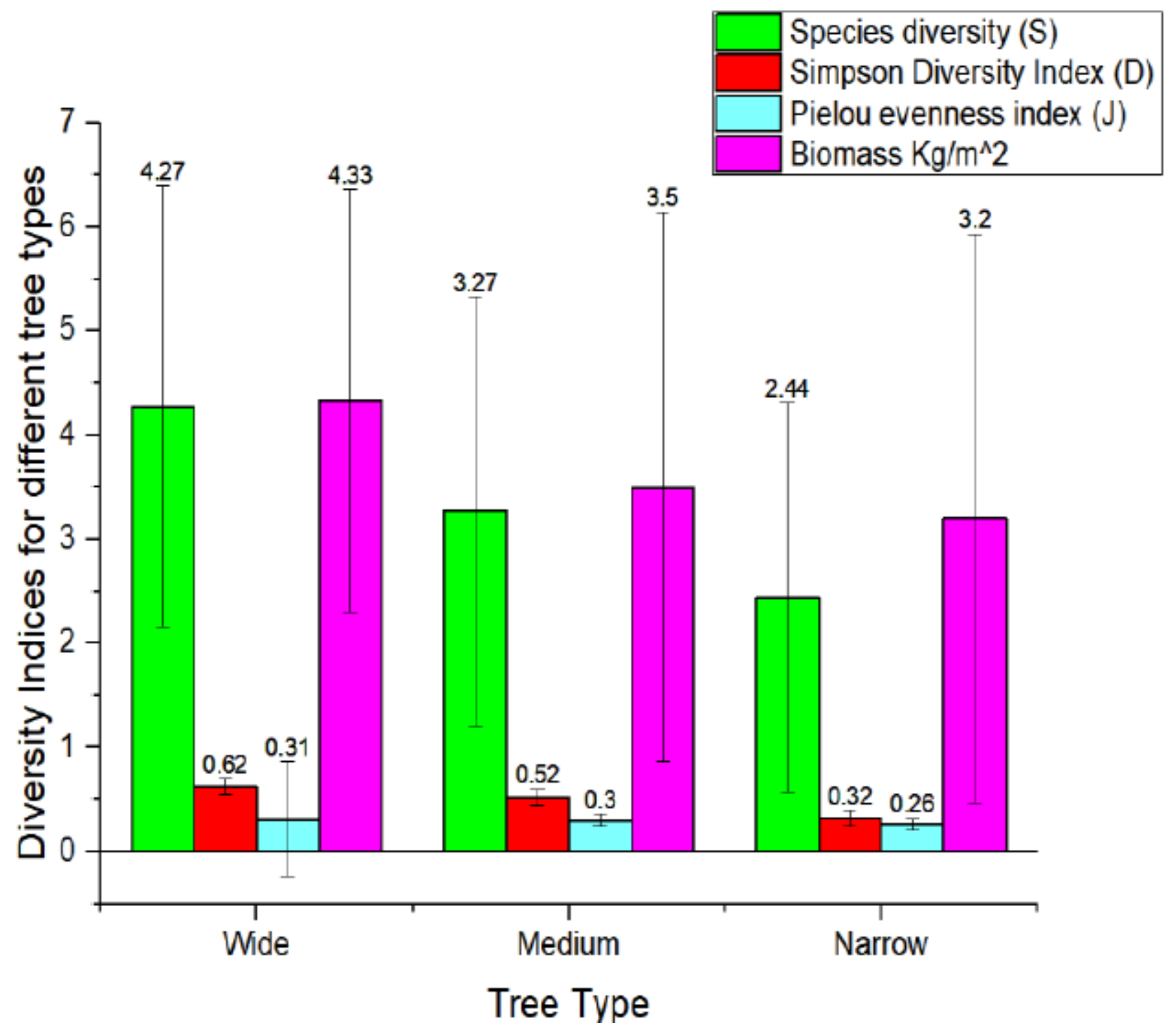

Figure 3

Diversity indices for different tree types 


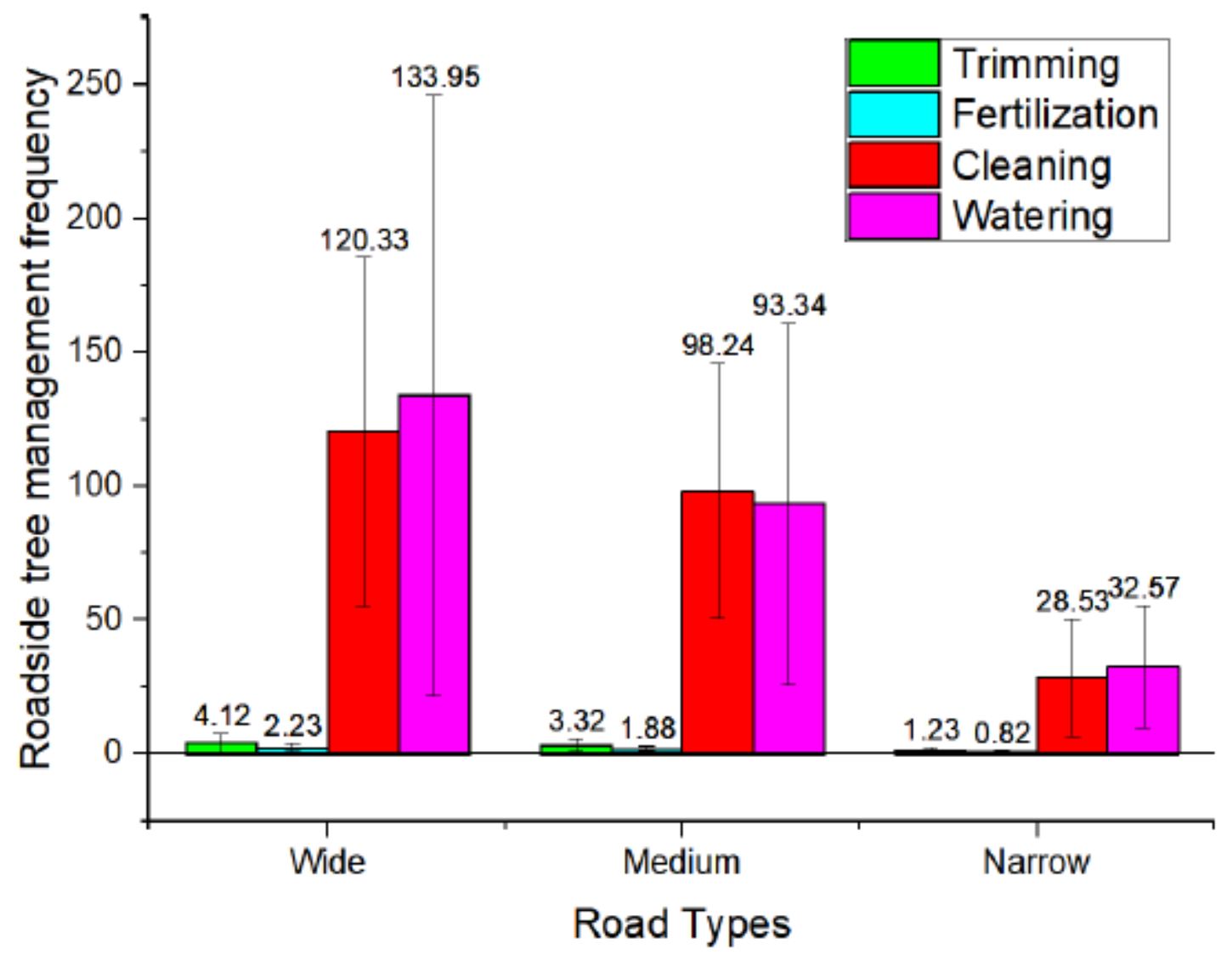

Figure 4

Roadside tree management activity 


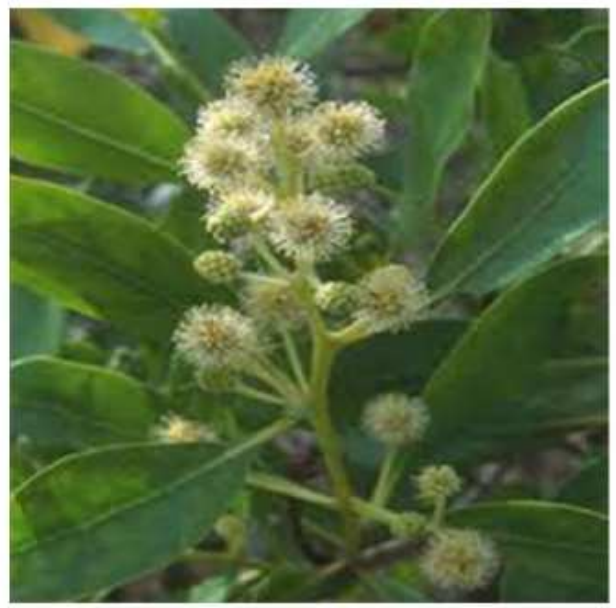

Conocarpus erectus

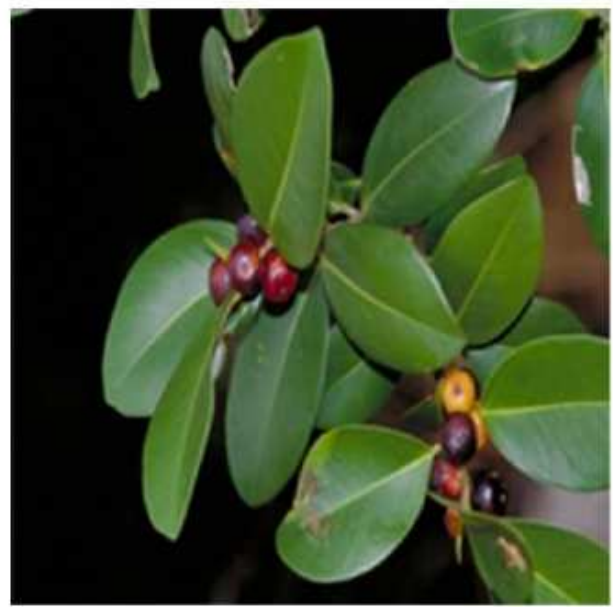

Ficus microcarpa

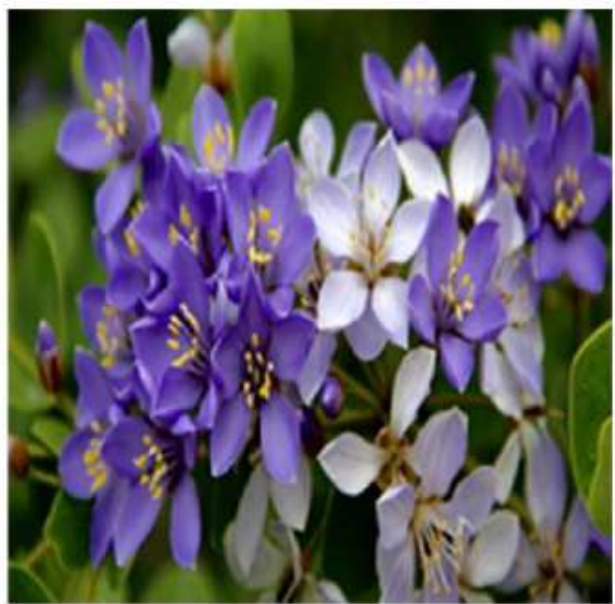

Guaiacum officinale

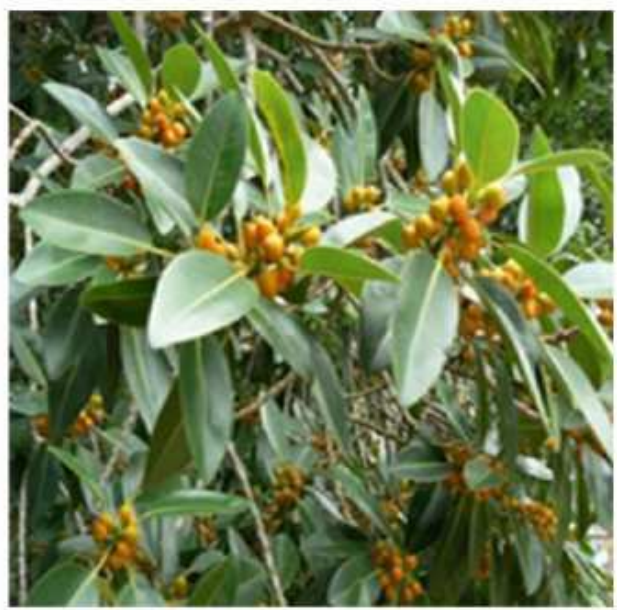

Ficus rubiginosa

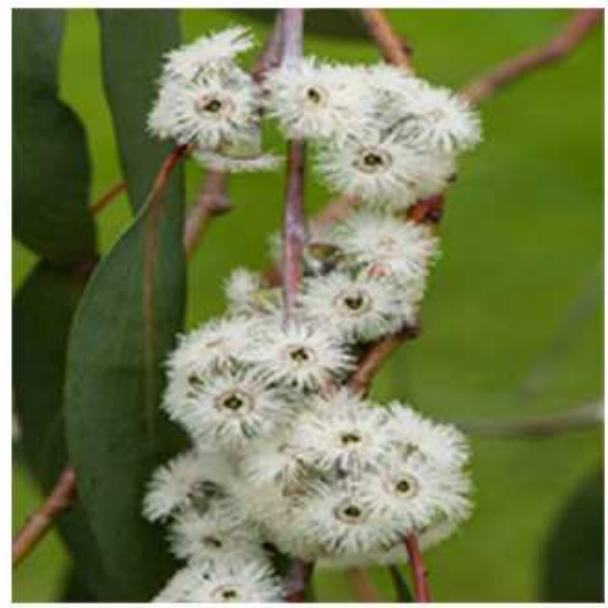

Eucalyptus pauciflora

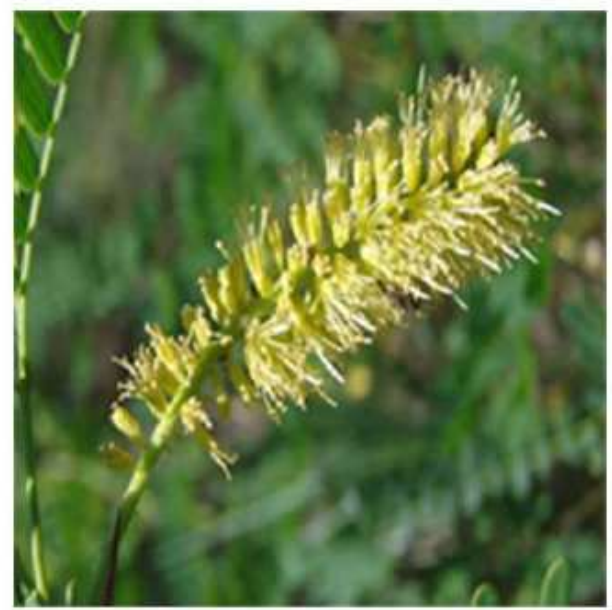

Prosopis juliflora

Figure 5

Flowers of common non-native trees species in Karachi 